\title{
Heritability of Phenotypes Associated with Glucose Homeostasis and Adiposity in a Rural Area of Brazil
}

\author{
Geórgia G. Pena ${ }^{1}$, Míriam Santos Dutra ${ }^{2,3}$, Andrea Gazzinelli ${ }^{1}$, Rodrigo Corrêa-Oliveira ${ }^{3}$ and \\ Gustavo Velasquez-Melendez ${ }^{1 *}$ \\ ${ }^{1}$ Departamento de Enfermagem Materno-Infantil e Saúde Pública, Escola de Enfermagem, Universidade Federal de Minas Gerais, Escola \\ de Enfermagem, Avenida Alfredo Balena 190, Belo Horizonte, MG 30130-100, Brazil \\ ${ }^{2}$ Departamento de Bioquímica e Imunologia. Universidade Federal de Minas Gerais, Belo Horizonte, MG. Rua Augusto de Lima, 1715, \\ Barro Preto, Belo Horizonte, Minas Gerais, CEP 30190-002, Brazil \\ ${ }^{3}$ Laboratório de Imunologia Celular e Molecular, Centro de Pesquisas René Rachou/FIOCRUZ, Augusto de Lima 1715, Barro Preto, \\ Belo Horizonte, Minas Gerais, CEP 30190-002, Brazil
}

\section{Summary}

We aimed to estimate the heritability and genetic correlation between glucose homeostasis and adiposity traits in a population in a rural community in Brazil. The Jequitinhonha Community Family Study cohort consists of subjects aged $\geq 18$ years residing in rural areas in Brazil. The data on the following traits were assembled for 280 individuals $(51.7 \%$ women): body mass index (BMI), body fat percentage, waist and mid-upper arm circumferences, triceps skinfold, conicity index, insulin, glucose, high-density lipoprotein cholesterol (HDLc), triglycerides and C-reactive protein. Extended pedigrees were constructed up to the third generation of individuals using the data management software PEDSYS. The heritability and genetic correlations were estimated using a variance component method. The age- and sex-adjusted heritability values estimated for insulin $\left(h^{2}=52 \%\right)$, glucose $\left(h^{2}=51 \%\right)$, HDLc $\left(h^{2}=58 \%\right)$, and waist circumference (WC; $h^{2}=49 \%$ ) were high. Significantly adjusted genetic correlations were observed between insulin paired with each of the following phenotypes; (BMI; $\rho \mathrm{g}=0.48)$, WC $(\rho \mathrm{g}=0.47)$ and HDLc $(\rho \mathrm{g}=-0.47)$. The homeostasis model assessment of insulin resistance (HOMA-IR) was genetically correlated with BMI $(\rho \mathrm{g}=0.53)$ and HDLc $(\rho \mathrm{g}=-0.58)$. The adjusted genetic correlations between traits were consistently higher compared with the environmental correlations. In conclusion, glucose metabolism and adiposity traits are highly heritable and share common genetic effects with body adiposity traits.

Keywords: Genetics, heritability, variance components, obesity, adiposity, glucose, insulin

\section{Introduction}

Insulin resistance, type 2 diabetes and obesity are major determinants of cardiovascular disease, mortality and other complications (Reaven, 1997; Godsland et al., 2011; Bo et al., 2012; Cameron et al., 2013). Diabetes is considered as an accelerating factor (Wagenknecht et al., 2003; Godsland et al., 2011).

*Corresponding author: GUSTAVO VELASQUEZ-MELENDEZ, Universidade Federal de Minas Gerais, Escola de EnfermagemAvenida Alfredo Balena, 190-Belo Horizonte, 30130-100, Brazil. Tel: +55 313409 9868; Fax +55 313409 9830; E-mail: guveme@ufmg.br
In addition, environmental factors, such as sedentary lifestyle and high-energy diet, also contribute to the development of diabetes (Healy et al., 2008; He et al., 2012; Bhopal, 2013). Controversy exists regarding the temporal sequence of the components of the pathophysiology of type 2 diabetes, as these processes apparently begin with a reduced response to insulin, called insulin resistance (Godsland et al., 2011).

Studies have indicated that alterations in glucose metabolism might reflect chronic inflammation associated with the expansion of adipose tissue (Bastard et al., 2006). In general, increasing the metabolic activity and expansion of adipose tissue increases the production of free fatty acids and inflammatory factors (Greenberg \& Obin, 2006). Thus, being overweight might lead to a loss of homeostatic control 
or the formation of part of a cluster of other metabolic states, such as insulin resistance, hypertension, chronic inflammation and a pre-thrombotic state, which contribute to the acceleration of the development of atherosclerosis (Schmidt et al., 1996). Epidemiological studies have shown wide controversy associated with evidence that the components of metabolic syndrome simultaneously occur more often than expected (Schmidt et al., 1996).

This effect could reflect the fact that these factors could act together as important genetic determinants or these factors might be dependent on different environmental factors. Indeed, a number of studies have identified a genetic influence on phenotypes associated with metabolic disorders that include multiple measures of adiposity (Rice et al., 1999), hyperinsulinemia and insulin resistance (Mayer et al., 1996). These results are consistent in population studies of twins and large family pedigrees, showing moderate and high heritability of various traits associated with anthropometric, inflammatory, serum lipids and glucose levels (Souren et al., 2007; Sung et al., 2009; Valle et al., 2011; Rao et al., 2012).

The assessment of the heritability of anthropometric and biochemical phenotypes could provide the basis for analysis and more evidence for the linkage detection of metabolic pathways involved in the development of these chronic diseases. However, many aspects of the genetic contribution to these diseases remain elusive, particularly in admixed populations, such as Brazilians (Parra et al., 2003; Pimenta et al., 2006). In addition, which and how many specific genes are involved in these diseases and whether the genetic contribution has a minor or major effect, showing the pleiotropic effects of these genes, remains unknown (Pimenta et al., 2006). These issues have been poorly investigated in Brazilian populations, particularly in rural areas where the populations are reasonably homogeneous, environmental variation might be reduced and a relatively uniform genetic background of the population exists (Heutink \& Oostra, 2002), providing an attractive setting for the study of the heritability of complex quantitative traits (Velasquez-Melendez et al., 2007; Oliveira et al., 2008). Notably, in this study area, the influence of Caucasian individuals on the population is not clearly evident, with most of the individuals being native Brazilians and African descendants. Importantly, living in isolated areas presents clear familial intermarriage, increasing the potential inbreeding of the population. Moreover, Brazil is a country where a new phenomenon of rapid nutritional transitioning occurs, while other coexisting conditions, such as undernutrition, obesity and a high prevalence of metabolic syndrome, becomes more prevalent in urban and rural areas (Velasquez-Melendez et al., 2007; Aballay et al., 2013).

In emerging economies, although the rate of undernutrition has gradually been decreasing, obesity rates are increasing, and in poor populations, these extreme conditions coexist in low and middle-income countries, where gradual changes in the economy are accompanied by rapid changes in the epidemiology of different diseases.

The aim of the present study was to estimate the heritability of the phenotypes associated with insulin resistance (glucose, fasting insulin and homeostasis model assessment of insulin resistance-HOMA-IR), adiposity anthropometric measures (body mass index-BMI, waist circumferenceWC and mid-upper arm circumference-MUAC), lipids levels (triglycerides and HDLc) and C-reactive protein (CRP) as an inflammatory marker. In addition, we estimated the environmental and genetic correlations using adjusted models to verify evidence of pleiotropic hypotheses between these traits. This study was developed in an underdeveloped area, where governmental social programs have yet to show any effect on health quality and care.

\section{Materials and Methods}

\section{Study Area and Design}

A cross-sectional population-based study was conducted in 2004 in the village of Virgem das Graças, a rural area in the municipality of Ponto dos Volantes, and this community is located in a semiarid region of Jequitinhonha Valley, Minas Gerais State, Brazil. The sample was obtained from the village of Taboca and four widely dispersed hamlets, Cardoso 1, Cardoso 2, Cardoso 3 and Suçuarana, which are located along two streams between 1 and $5 \mathrm{~km}$ from the main village of Taboca. Suçuarana is the remotest location at the highest elevation. Suçuarana has no direct access and can only be reached on foot or horseback. These rural villages and hamlets have no water treatment or sewage systems.

\section{Pedigree Data Collection}

All of the individuals living in the rural area were indiscriminately invited to participate in this study and a census was obtained of the population living in Virgem das Graças, which included 685 inhabitants. Of this total, 408 were aged greater than or equal 18 years, providing a base population for this study. Some inhabitants were excluded: pregnant women $(\mathrm{n}=7)$, individuals who did not give blood $(\mathrm{n}=35)$, people in the study who were traveling $(\mathrm{n}=44)$, those who had migrated to other areas $(n=11)$ and those who would not participate in the study $(n=31)$. A total of 280 eligible subjects were available to participate in this study. For the family data, in this same visit, each household was assigned a unique household number, and each resident was assigned a personal identity number (PIN). Information for the pedigree data were collected as previously described (Williams-Blangero \& 
Blangero, 2006). Briefly, pedigrees were constructed using the information gathered during interviews of each household. The birth date and place, gender, and the names of parents, siblings, and first- or second-degree relatives living in the village of each participant were registered for each home. If not previously registered, a PIN was assigned for each new parent, grandparent or sibling cited in the interviews. This information was used for the construction of multi-household extended pedigrees using the pedigree-based data management system-PEDSYS (Dyke, 1992). Two programs were used within PEDSYS: COUNTPED to identify the genealogical links in the file and to assign a number to each individual, corresponding to the pedigree to which he or she belongs; and PEDTRIM to simplify the pedigree through the removal of individuals who do not add information to the analysis.

The consent form and the protocols were approved through the National Ethics Committee of Brazil and the Ethics Committee from the Universidade Federal de Minas Gerais. Consent forms, written in Portuguese, were provided to each participant, who was provided adequate time to read the information and ask questions. Consent was obtained from each participant and documented with a signature on the consent form. All patients provided written informed consent prior to inclusion in this study, and all procedures were performed in person, in accordance with National, Institutional and NIH Guidelines.

\section{Pedigree Data Confirmation}

To confirm the genealogical links obtained at the interviews, the genotyping of 10 highly informative microsatellite markers was performed in all DNA samples (Table 1). Eight of the markers were purchased from ABI- Applied Biosystems ${ }^{\mathrm{TM}}$ (Carlsbad, CA, USA) as part of a Linkage Mapping Set (LMS) v2.5, and two markers were custom made. To design these markers, the DNA samples were extracted from blood clots obtained from the population for which pedigree information was available (Dutra et al., 2013). Polymerase chain reactions (PCRs) were performed in a total of $5 \mu \mathrm{L}$, containing $12.5 \mathrm{ng}$ DNA template, $2.2 \mu \mathrm{L}$ of standard buffer pre-mix, $2.5 \mathrm{pmol}$ of primers and 0.25 units of AmpliTaq Gold ${ }^{\mathrm{TM}}$ polymerase (Applied Biosystems $($, Foster City, CA, USA). The standard buffer premix contained 2.3X PCR Buffer II (Applied Biosystems (C), $6.9 \mathrm{mM} \mathrm{MgCl} 2,0.58 \mathrm{mM}$ dNTPs (Bioline $\bigodot$, Taunton, MA, USA) and $1 \mathrm{M}$ Betaine (Sigma-Aldrich $\subset$, Sant Louis, MO, USA). The PCRs were performed using the following program: $94^{\circ} \mathrm{C}$ for $10 \mathrm{~min}$, followed by $15 \mathrm{cy}-$ cles of $94^{\circ} \mathrm{C}$ for $20 \mathrm{~s}, 63-56^{\circ} \mathrm{C}$ for $60 \mathrm{~s}$, with $0.5^{\circ} \mathrm{C} / \mathrm{cycle}$ decrements, and $72^{\circ} \mathrm{C}$ for $60 \mathrm{~s}, 20$ cycles of $94^{\circ} \mathrm{C}$ for $20 \mathrm{~s}$, $56^{\circ} \mathrm{C}$ for $60 \mathrm{~s}$, and $72^{\circ} \mathrm{C}$ for $60 \mathrm{~s}$ and a final extension step at $72^{\circ} \mathrm{C}$ for $5 \mathrm{~min}$. Subsequently, the PCR products were denatured for $5 \mathrm{~min}$ at $95^{\circ} \mathrm{C}$. The fragment analysis was performed with MegaBace/1000 (GE Healthcare $\subseteq$, Buckinghamshire, UK) using the MegaBace ET550-R (GE Healthcare(C) as genotyping size standards. The size of the labeled fragments was determined using Fragment Profiler software (GE Healthcare $C$ ). Eventual typing errors and genotype and complex family structure incompatibilities were identified and corrected using Pedcheck software (O'Connell \& Weeks, 1998, Shugart \& Wang, 2012). Heterozygosity and the polymorphic information content (PIC) were calculated using the free online software PICcalc (Nagy et al., 2012).

\section{Anthropometric Traits}

Trained interviewers collected the anthropometric data according to a standard protocol (Lohman et al., 1988). Weight was measured to the nearest $0.1 \mathrm{~kg}$ using a calibrated scale, and height was determined to the nearest $1 \mathrm{~mm}$ using a wallmounted stadiometer. The measures were obtained from individuals wearing light clothes without shoes. The circumferences were measured using inelastic plastic fiber tape placed directly on the skin with both feet and arms hanging freely. The measurements were obtained at the end of expiration at the midpoint between the lowest rib margin and the iliac crest. The MUAC was measured at the midpoint to the nearest $1 \mathrm{~mm}$ at the midpoint between the acromial and olecranon, and the triceps skinfold (SKT) was measured to the nearest 1 mm using a Lange ${ }^{\odot}$ (Beta Technology Incorporated, Cambridge, MD, USA) skinfold caliper. These measurements were repeated three times. The BMI was obtained after dividing the weight in kilograms by the square of the height in meters $\left(\mathrm{BMI}=\right.$ weight $/$ height $\left.^{2}, \mathrm{~kg} / \mathrm{m}^{2}\right)$. The tetrapolar frequency bioelectrical impedance (model Quantum II, RJL ${ }^{\odot}$ Systems, Inc., Detroit, MI, USA) was used to measure the whole-body electrical resistance and impedance with the participant lying flat in the horizontal position. Estimates of the total body fat $(\mathrm{BF})$ and percent $\mathrm{BF}(\% \mathrm{BF})$ were calculated using CYPRUS 1.2 software $\left(\mathrm{RJL}^{\odot}\right.$ Systems, Detroit, MI, USA).

\section{Biochemical Analyses}

The fasting blood samples were collected in Vacutainer ${ }^{\odot}$ (BD Bioscience, Franklin Lakes, NJ, USA) tubes at central examination sites in the sampled villages and hamlets. The blood samples were immediately placed on wet ice and transported to the laboratory of the René Rachou Research Center of the Fundação Oswaldo Cruz, in Belo Horizonte, where the samples were processed and stored until further use. The diagnosis of insulin resistance was estimated using the Homeostasis Model Assessment (HOMA-IR), a reliable indicator of insulin resistance, obtained using a formula that considers the 
fasting insulin $(\mu \mathrm{U} / \mathrm{mL})$ and fasting glucose $(\mathrm{mmol} / \mathrm{L}) / 22.5$ levels (Matthews et al., 1985). Low HOMA-IR values indicate high insulin sensitivity, whereas high HOMA-IR values indicate insulin resistance.

Total cholesterol, HDLc and triglycerides were measured using commercially available enzymatic reagents adapted to an auto analyzer (Cobas-Miraplus, Roche ${ }^{\odot}$ Crumlin, UK). The concentration of HDLc was also determined using a colorimetric enzymatic assay based on the precipitation of low-density lipoprotein cholesterol (LDLc) and very LDLc fractions using phosphotungstic acid and magnesium chloride.

\section{Statistical Methods}

The genealogical data were entered into a PEDSYS, which facilitated rapid pedigree reconstruction and the determination of pedigree sizes (Dyke, 1992). The phenotypes studied included glucose homeostasisand adiposity traits. The basic descriptive statistics, including means and standard deviations, were estimated using the STATA statistical software, version 12.0. The heritability $\left(h^{2} \pm\right.$ standard error) for each phenotype was defined based on a standard quantitative genetic theory, which defines heritability as the proportion of the total phenotypic variance due to additive genetic effects. The heritability was calculated as the ratio of additive genetic variance to total phenotypic variance $\left(\sigma^{2}\right.$ genetic $/ \sigma^{2}$ phenotype). When the normality assumption did not hold for a specific trait, natural log-transformation was applied, followed by a new data assessment (Hopper \& Mathews, 1983; Lange \& Boehnke, 1983). The residual heritability was used to reflect the proportion of variance attributable to additive genetic effects after considering covariate traits, such as sex and age.

The relationships between log transformed measures of glucose metabolism and adiposity traits were estimated based on pair-wise genetic and environmental correlations. The phenotypic correlation $(\rho \mathrm{g})$ between traits can be partitioned into additive genetic ( $\rho \mathrm{g} \pm$ standard error) and random environmental ( $\rho \mathrm{e} \pm$ standard error) components. In addition, complete and incomplete pleiotropy were assessed (Almasy et al., 1997). Complete pleiotropy was indicated with a $\rho \mathrm{g}$ equal to one (the $\rho \mathrm{g}$ was not significantly different from 1 ). When the $\rho \mathrm{g}$ is significantly different from \pm 1.0 and significantly different from zero, the pleiotropy is interpreted as incomplete. The significance of all parameters was calculated using a likelihood ratio test based on the statistic $-2[\ln (\operatorname{Lr})-$ $\ln (\mathrm{Lc})]$, which compares the likelihood of a restricted model $(\mathrm{Lr})$ to the likelihood of a complete model $(\mathrm{Lc})$ in which the parameter $\left(h^{2}, \mathrm{c}^{2}, \rho\right.$ e or $\left.\rho \mathrm{g}\right)$ is set to zero. The likelihood ratio test statistic is asymptotically distributed as a $\chi^{2}$ distribution with the number of degrees of freedom equal to the number of parameters fixed in the restricted model. All variables were considered significant at $\mathrm{p} \leq 0.05$. The analyses were implemented in the Sequential Oligogenic Linkage Analysis Routine (SOLAR; Texas, USA) software package (Almasy \& Blangero, 1998).

\section{Results}

\section{Characteristics of Participants and Pedigree Descriptive Analyses}

Family relationship links were established between individuals in the data set based on detailed family information collected during the fieldwork. After confirmation of this information through the genotyping of informative microsatellite markers (Table 1), relative pairs in the whole and subset family population are shown in Table 2 . The extensive in-depth pedigree information facilitated the reconstruction of a single pedigree, containing a total of 1464 individuals and 280 sampled individuals (136 men and 144 women). We defined a total of 544 nuclear families and 485 founders from the pedigree data (data not shown). The sampled pedigree contained 4009 pairs of relatives, including 149 parent-offspring, 114 siblings, 10 grandparent-grandchild, 172 avuncular, 2 halfsibling and 317 first cousin pairs, which were informative for genetic analysis.

Descriptive statistics, including means and standard deviations for anthropometric and biochemical traits (Table 3), were obtained from 280 subjects ranging in age from 18 to 85 years $(44.56 \pm 17.29)$. As shown, BMI, BF, MUAC, SKT, fasting insulin and total cholesterol were higher in female than in male individuals.

Estimates of the variance components from the quantitative genetic analysis, based on maximum-likelihood tests, are shown in Table 4 . The heritability $\left(h^{2} \pm\right.$ standard error) estimates were adjusted for different co-variables. Considering the anthropometric traits, the heritability estimates were high in all models. The crude heritability estimates ranged from 18 to $52 \%$. The HDLc $\left(h^{2}=0.52 \pm 0.12, \mathrm{p}<0.001\right)$, WC $\left(h^{2}=0.50 \pm 0.11, \mathrm{p}<0.001\right)$ and insulin $\left(h^{2}=\right.$ $0.50 \pm 0.13, \mathrm{p}<0.001)$ showed higher values. When the heritabilities were adjusted for age, sex and smoking habits, higher estimates remained for WC $\left(h^{2}=0.49 \pm 0.11, \mathrm{p}<\right.$ $0.001)$, BMI $\left(h^{2}=0.47 \pm 0.11, \mathrm{p}<0.001\right)$, and body fat $\left(\mathrm{BF} \% ; h^{2}=0.42 \pm 0.11, \mathrm{p}<0.001\right)$. The biochemical traits were adjusted for age, sex, smoking habits and WC. Estimates were obtained for HOMA-IR $\left(h^{2}=0.28 \pm 0.13\right.$, $\mathrm{p}=$ $0.005)$, CRP $\left(h^{2}=0.20 \pm 0.13, \mathrm{p}=0.04\right)$, glucose $\left(h^{2}=\right.$ $0.51 \pm 0.14, \mathrm{p}<0.001)$, fasting insulin $\left(h^{2}=0.52 \pm 0.14\right.$, $\mathrm{p}<0.001)$ and HDLc $\left(h^{2}=0.58 \pm 0.12, \mathrm{p}<0.001\right)$.

Because genetic and environmental factors cooperatively contribute to the development of insulin resistance, which 


\section{G. G Pena et al.}

Table 1 Information for the microsatellite markers used for genotyping.

\begin{tabular}{|c|c|c|c|c|c|c|}
\hline Microsatellite & LMS v2.5 Panel & Dye & Product range (bp) & Het $_{\text {obs }}$ & $\mathrm{PIC}^{*}$ & $\mathrm{~N}^{\circ}$ of alleles \\
\hline Myc10_10 & Custom made & FAM $^{\mathrm{TM}}$ & $100-120$ & 0.84 & 0.83 & 10 \\
\hline D11S4102 & 62 & $\mathrm{FAM}^{\mathrm{TM}}$ & $140-172$ & 0.74 & 0.72 & 16 \\
\hline Myc10_7 & Custom made & $\mathrm{FAM}^{\mathrm{TM}}$ & $190-210$ & 0.85 & 0.84 & 7 \\
\hline D11S4151 & 15 & $\mathrm{FAM}^{\mathrm{TM}}$ & $331-345$ & 0.82 & 0.80 & 7 \\
\hline D11S4191 & 15 & $\mathrm{VIC}^{\mathrm{TM}}$ & $89-119$ & 0.78 & 0.74 & 15 \\
\hline D6S289 & 8 & $\mathrm{VIC}^{\mathrm{TM}}$ & $160-182$ & 0.88 & 0.87 & 11 \\
\hline D2S117 & 3 & $\mathrm{VIC}^{\mathrm{TM}}$ & $190-220$ & 0.88 & 0.88 & 15 \\
\hline D11S914 & 62 & $\mathrm{VIC}^{\mathrm{TM}}$ & $279-291$ & 0.78 & 0.74 & 6 \\
\hline D2S2382 & 4 & $\mathrm{VIC}^{\mathrm{TM}}$ & $296-336$ & 0.81 & 0.79 & 20 \\
\hline D2S325 & 3 & $\mathrm{NED}^{\mathrm{TM}}$ & $154-184$ & 0.83 & 0.81 & 15 \\
\hline
\end{tabular}

*PIC: Polymorphism Informative Content.

Table 2 Relative pairs in the whole and subset family population.

\begin{tabular}{lll}
\hline Relative pairs & $\begin{array}{l}\text { Whole (n) } \\
\text { pedigree }\end{array}$ & $\begin{array}{l}\text { Phenotype } \\
\text { subset (n) }\end{array}$ \\
\hline Pedigree/pedigree members & $21 / 1464$ & 280 \\
Parent-offspring & 1735 & 149 \\
Siblings-siblings & 799 & 114 \\
Grandparents-grandchild & 2462 & 10 \\
Avuncular & 1690 & 172 \\
Half-siblings & 38 & 2 \\
1st Cousins & 1802 & 317 \\
Total relationships & 43,340 & 4009 \\
\hline
\end{tabular}

leads to diabetes, pair-wise relationships were used to estimate the genetic correlations of glucose homeostasis traits (glucose, fasting insulin and HOMA-IR) with anthropometric (BMI, WC and MUAC) and lipid traits (HDLc, triglycerides). The genetic $(\rho \mathrm{g})$ and environmental correlation $\left(\rho_{\mathrm{e}}\right)$ estimates were adjusted for sex and age as shown in Table 5 . A significant positive correlation of fasting insulin with BMI $(\rho \mathrm{g}=0.48 \pm 0.16)$ and WC $(\rho \mathrm{g}=0.47 \pm 0.16)$ was observed in both unadjusted (data not shown) and adjusted models, and these values were negatively correlated with HDLc only in the adjusted model $(\rho \mathrm{g}=-0.47 \pm 0.18)$. HOMA-IR was negatively correlated with HDLc in both models $(\rho \mathrm{g}=-0.58 \pm$ 0.21 ) and positively correlated with BMI only in the adjusted model. There were no significant correlations between fasting glucose and either anthropometric or biochemical traits in the adjusted analysis. Based on the likelihood-ratio test, there was no evidence of complete pleiotropy $\left(\rho_{\mathrm{g}}= \pm 1\right)$ in any of the significant correlations. The proportions of total additive genetic variance due to the shared genes varied between $21 \%$ (HOMA-IR-HDLc) and 44\% (fasting insulin-BMI).

There were significant environmentally adjusted correlations between the following traits: fasting glucose-WC $\left(\rho_{\mathrm{e}}=\right.$
$0.30 \pm 0.14, \mathrm{p}=0.04)$, fasting insulin-BMI $\left(\rho_{\mathrm{e}}=0.33 \pm\right.$ $0.14, \mathrm{p}=0.04)$, fasting insulin-MUAC $\left(\rho_{\mathrm{e}}=0.33 \pm 0.12\right.$, $\mathrm{p}=0.02)$, fasting insulin-HDLc and HOMA-IR-MUAC $\left(\rho_{\mathrm{e}}=0.29 \pm 0.11, \mathrm{p}=0.03\right)$.

\section{Discussion}

In this study, we estimated the heritability of the phenotypes associated with glucose homeostasis, adiposity and lipids using a variance components method in a large pedigree data set. These estimates explain the percent trait variance resulting from additive genetic effects. Highly significant genetic hereditability $\left(h^{2}\right)$ for glucose and fasting insulin traits was observed, even in traits adjusted according to sex, age and waist circumference. However, these estimates were attenuated for HOMA-IR. The heritability estimates for glucose homeostasis traits ranged between $20 \%$ and 58\%. Similar to another study conducted in a rural area of Brazil, polygenic heritability estimates, adjusted for covariates, are high for waist circumference and BMI but relatively different for glucose metabolism traits (Oliveira et al., 2008).

The results of the present study are consistent with other studies performed in different sets of populations in different geographical regions worldwide (Austin et al., 1993; Arya et al., 2002; Xiang et al., 2002; Lin et al., 2005; Bastarrachea et al., 2007; Shah et al., 2009; Zabaneh et al., 2009; Ghosh et al., 2010; Lee et al., 2010; Valle et al., 2011). However, these results are the first demonstration that phenotypes are associated with glucose metabolism and obesity in a Brazilian population, using large pedigree data from individuals in rural areas.

Low estimates of heritability for fasting insulin (8\%) and HOMA-IR (8\%) and moderate estimates for glucose $(28 \%)$ have been observed in African-descendants and Spanish populations (Henkin et al., 2003). In addition, in healthy families of Caucasian, moderate heritability estimates (between 20\% 
Table 3 Clinical characteristics of individuals according to sex.

\begin{tabular}{|c|c|c|c|c|c|c|c|c|c|c|c|c|c|}
\hline \multirow[b]{3}{*}{ Variables } & \multicolumn{8}{|l|}{ Sex } & & & & & \multirow[b]{3}{*}{ p value ${ }^{*}$} \\
\hline & \multicolumn{4}{|c|}{ Male } & \multicolumn{4}{|c|}{ Female } & \multicolumn{4}{|c|}{ Total } & \\
\hline & $\mathrm{N}$ & $\begin{array}{l}\text { Frequency } \\
\text { or Average }\end{array}$ & \pm & SD & $\mathrm{N}$ & $\begin{array}{l}\text { Frequency } \\
\text { or Average }\end{array}$ & \pm & $\pm \mathrm{SD}$ & $\mathrm{N}$ & $\begin{array}{l}\text { Frequency } \\
\text { or Average }\end{array}$ & \pm & $\mathrm{SD}$ & \\
\hline Age (years) & 135 & 44.69 & \pm & 16.96 & 145 & 44.44 & \pm & 17.65 & 280 & 44.56 & \pm & 17.29 & 0.90 \\
\hline \multicolumn{14}{|l|}{ Skin Color } \\
\hline White & 48 & 35.56 & & & 87 & 44.83 & & & 113 & 40.36 & & & 0.11 \\
\hline Nonwhite & 65 & 64.44 & & & 80 & 55.17 & & & 167 & 59.64 & & & \\
\hline \multicolumn{14}{|l|}{ Marital Status } \\
\hline Single & 29 & 21.48 & & & 21 & 14.48 & & & 50 & 17.86 & & & 0.005 \\
\hline $\begin{array}{l}\text { Married/Living with } \\
\text { a partner }\end{array}$ & 102 & 75.56 & & & 105 & 72.41 & & & 207 & 73.93 & & & \\
\hline $\begin{array}{l}\text { Separated/Divorced/ } \\
\text { Widowed }\end{array}$ & 4 & 2.96 & & & 19 & 13.10 & & & 23 & 8.21 & & & \\
\hline Smoking Status & & & & & & & & & & & & & $<0.001$ \\
\hline Current Smoker & 48 & 35.56 & & & 17 & 11.72 & & & 65 & 23.21 & & & \\
\hline Ex-smoker & 50 & 37.04 & & & 116 & 80.00 & & & 166 & 59.29 & & & \\
\hline Nonsmoker & 37 & 27.41 & & & 12 & 8.28 & & & 49 & 17.50 & & & \\
\hline BMI Status & & & & & & & & & & & & & $<0.001$ \\
\hline Normal & 118 & 87.41 & & & 91 & 62.76 & & & 209 & 74.64 & & & \\
\hline Overweight & 15 & 11.11 & & & 38 & 26.21 & & & 53 & 18.93 & & & \\
\hline Obese & 2 & 1.48 & & & 16 & 11.03 & & & 18 & 6.43 & & & \\
\hline BMI $\left(\mathrm{kg} / \mathrm{m}^{2}\right)$ & 136 & 21.98 & \pm & 2.91 & 144 & 24.21 & & 4.26 & 280 & 23.13 & \pm & 3.82 & $<0.001$ \\
\hline Body Fat (\%) & 136 & 13.45 & \pm & 4.41 & 144 & 33.64 & & 7.81 & 280 & 23.83 & \pm & 11.96 & $<0.001$ \\
\hline Body Fat (kg) & 136 & 8.45 & \pm & 3.94 & 144 & 19.39 & & 7.649 & 280 & 14.08 & \pm & 8.21 & $<0.001$ \\
\hline MUAC $(\mathrm{cm})$ & 136 & 27.51 & \pm & 2.60 & 144 & 28.63 & & 3.50 & 280 & 28.09 & \pm & 3.14 & 0.003 \\
\hline Triceps Skinfold (mm) & 136 & 8.37 & \pm & 3.676 & 144 & 18.33 & & 5.56 & 280 & 13.49 & \pm & 6.87 & $<0.001$ \\
\hline Conicity Index & 135 & 1.22 & \pm & 0.07 & 144 & 1.22 & & 0.08 & 279 & 1.22 & \pm & 0.78 & 0.66 \\
\hline WC (cm) & 136 & 80.45 & \pm & 8.51 & 144 & 81.29 & & 10.99 & 280 & 80.93 & \pm & 9.86 & 0.52 \\
\hline HOMA - IR & 105 & 0.87 & \pm & 1.23 & 126 & 1.12 & & 0.87 & 231 & 1.01 & \pm & 1.05 & 0.07 \\
\hline Glucose (mg/dL) & 126 & 90.53 & \pm & 22.65 & 138 & 90.32 & & 18.21 & 264 & 90.42 & \pm & 20.41 & 0.93 \\
\hline Fasting Insulin $(\mu \mathrm{U} / \mathrm{mL})$ & 107 & 3.76 & \pm & 4.39 & 126 & 5.00 & & 3.61 & 233 & 4.43 & \pm & 4.03 & 0.01 \\
\hline CRP & 114 & 0.35 & \pm & 0.70 & 127 & 0.38 & & 0.51 & 241 & 0.37 & \pm & 0.61 & 0.72 \\
\hline HDL (mg/dL) & 126 & 49.75 & \pm & 13.12 & 138 & 51.19 & & 14.46 & 264 & 50.50 & \pm & 13.83 & 0.39 \\
\hline Cholesterol (mg/dL) & 126 & 193.58 & \pm & 41.59 & 138 & 207.04 & & 51.86 & 264 & 200.62 & \pm & 47.63 & 0.02 \\
\hline Triglycerides (mg/dL) & 126 & 107.17 & \pm & 54.15 & 138 & 121.66 & & 67.23 & 264 & 114.75 & \pm & 61.66 & 0.05 \\
\hline
\end{tabular}

${ }^{*}$ t-test or chi-squared test, between sex. SD: standard deviation; BMI: body mass index; MUAC: mid-upper arm circumference; HOMA-IR: homeostasis model assessment-insulin resistance; CRP: C-reactive protein; HDL: high-density lipoprotein; WC: waist circumference. H: height.

and 23\%) were also observed, when analyzing fasting glucose, insulin and insulin resistance (Freeman et al., 2002). However, in highly consanguineous healthy Omani Arab (Bayoumi et al., 2007) and European families with increased susceptibility to type 2 diabetes, high estimates of genetic contribution for insulin resistance (37\%) and fasting glucose (72\%) were reported (Mills et al., 2004). Moreover, in Asian Indian families, moderate and high heritability, similar to the present study, were observed for HOMA-IR (22\%), glucose $(37 \%)$, and HDLc (53\%) (Zabaneh et al., 2009). Other study designs have shown evidence of glucose homeostasis and high level lipid concentrations (Laws et al., 1989), the significant heritability of insulin in twins (53\%) (Mayer et al., 1996) and increased insulin concentrations in the nondiabetic offspring of diabetic parents (Haffner et al., 1988).

We also observed consistent positive correlations with glucose metabolism traits, such as fasting insulin and HOMA-IR, and adiposity indices and negative correlations with HDLc. All correlations remained significant after adjusting for potentially confounding variables. However, we observed no association between fasting glucose and either adiposity or lipid traits. These correlations were not extended to the novel 
Table 4 Heritability of glucose homeostasis and adiposity traits adjusted according to models adjusted for different variables.

\begin{tabular}{|c|c|c|c|c|c|c|}
\hline \multirow[b]{2}{*}{ Phenotype } & \multirow[b]{2}{*}{$\mathrm{N}$} & \multicolumn{2}{|c|}{ Crude heritability } & \multicolumn{2}{|c|}{ Adjusted heritability } & \multirow[b]{2}{*}{$\mathrm{p}$-value } \\
\hline & & $\mathrm{h}^{2} \pm \mathrm{SE}$ & p-value & $\mathrm{N}$ & $\mathrm{h}^{2} \pm \mathrm{SE}$ & \\
\hline Body fat $(\%)$ & 279 & $0.44 \pm 0.12$ & $<0.001$ & 279 & $0.42 \pm 0.11$ & $<0.001^{1}$ \\
\hline $\mathrm{WC}(\mathrm{cm})$ & 278 & $0.50 \pm 0.11$ & $<0.001$ & 278 & $0.49 \pm 0.11$ & $<0.001^{1}$ \\
\hline MUAC $(\mathrm{cm})$ & 279 & $0.30 \pm 0.10$ & $<0.001$ & 279 & $0.31 \pm 0.10$ & $<0.001^{1}$ \\
\hline HOMA-IR & 230 & $0.35 \pm 0.14$ & 0.002 & 229 & $0.28 \pm 0.13$ & $0.005^{2}$ \\
\hline Glucose (mg/dL) & 263 & $0.38 \pm 0.14$ & 0.001 & 262 & $0.51 \pm 0.14$ & $<0.001^{2}$ \\
\hline Fasting Insulin $(\mu \mathrm{U} / \mathrm{mL})$ & 232 & $0.50 \pm 0.13$ & $<0.001$ & 231 & $0.52 \pm 0.14$ & $<0.001^{2}$ \\
\hline $\mathrm{CRP}$ & 240 & $0.18 \pm 0.12$ & 0.03 & 239 & $0.20 \pm 0.13$ & $0.04^{2}$ \\
\hline $\mathrm{HDL}(\mathrm{mg} / \mathrm{dL})$ & 263 & $0.52 \pm 0.12$ & $<0.001$ & 262 & $0.58 \pm 0.12$ & $<0.001^{2}$ \\
\hline
\end{tabular}

All measures were $\log _{\mathrm{e}}$ transformed prior to analysis. $h^{2}=$ heritability. SE: standard error; BMI: body mass index; MUAC: mid-upper arm circumference; HOMA-IR: homeostasis model assessment-insulin resistance; CRP: C-reactive protein; HDL: high-density lipoprotein; WC: waist circumference. SKT: triceps skinfold.

${ }^{1}$ Adjusted by sex and age and smoking habits.

${ }^{2}$ Adjusted by sex, age and WC.

risk factors associated with inflammation, such as CRP. We observed that all correlations between these studied traits were higher when compared with the environmental correlations.

Our results are consistent with a number of studies that have investigated the relationship between insulin resistance phenotypes, adiposity, dyslipidemia and hypertension (Brown et al., 2003; Oliveira et al., 2008; Warren et al., 2005; Reilly $\&$ Rader, 2003). Highly significant positive correlations were also observed between fasting insulin or HOMA-IR and adiposity indices in other studies (Mills et al., 2004; Sung et al., 2009). It has been suggested that the genes influencing insulin resistance and glucose metabolism might exhibit pleiotropic effects with genes that regulate central and global adiposity and the levels of HDLc in the body, suggesting that the genes underlying an increase in global and central adiposity might also influence insulin resistance.

The magnitudes of genetic correlations between anthropometric and biochemical traits might suggest the existence of pleiotropic effects of genetic factors. In general, our results of bivariate correlations imply that the same set of genes or additive genes contribute to the increase in fasting insulin, insulin resistance, and adiposity and the decrease in HDLc. The significant additive genetic correlations showed $\mathrm{p}$ values different from zero and one, confirming incomplete pleiotropy.

Similar to other studies of heritability, the present study has limitations. The heritability estimates reflect the ratio of genetic and total variance and can therefore be influenced through population variance and structure, and disease and treatment effects. In this study, we observed that many genes contribute to the variability of each phenotype, potentially involving different metabolic pathways.

The results presented in this study are unique, as these observations were obtained from a rural population subjected to nutritional and epidemiological transitions. In this area, the prevalence of physically active adults is high, as the primary activity of the active population is farming, suggesting that the working members spend more energy in their daily routines. However, the levels of leisure time spent performing physical activities are low and follow patterns similar to those observed in urban areas (Bicalho et al., 2010). These observations are in contrast with those from sedentary populations, which have been assessed in other studies showing a potentially high risk for developing chronic diseases (Matos \& Ladeia, 2003).

Moreover, all significant correlations between these traits showed incomplete pleiotropy. Pleiotropy is typically implied when a gene(s) controls multiple phenotypic traits. There might be a mediation of the effects of a gene for one trait onto another or even the confounding of effects by a third gene.

In conclusion, the results of univariate and bivariate quantitative genetic analyses reinforce the hypothesis that a common set of genes has at least partial pleiotropic effects on both insulin levels and insulin resistance associated with adiposity and the levels of HDLc in the body. These results confirm this 
Table 5 Pair-wise correlation adjusted between glucose homeostasis with anthropometrics and lipid traits.

\begin{tabular}{|c|c|c|c|c|c|}
\hline Phenotype pairs & $\mathrm{N}$ & $\rho g \pm \mathrm{SE}$ & $\mathrm{p}$ value $^{1}$ & $\rho e \pm \mathrm{SE}^{2}$ & $\rho \mathrm{p}^{3}$ \\
\hline Glucose- BMI & 280 & $0.05 \pm 0.22$ & 0.79 & $0.22 \pm 0.13$ & 0.15 \\
\hline Glucose-WC & 280 & $-0.12 \pm 0.22$ & 0.57 & $0.30 \pm 0.14^{2}$ & 0.18 \\
\hline Glucose-MUAC & 280 & $0.28 \pm 0.46$ & 0.56 & $0.20 \pm 0.12$ & 0.15 \\
\hline Glucose-HDLc & 264 & $-0.07 \pm 0.24$ & 0.74 & $-0.01 \pm 0.17$ & -0.01 \\
\hline Glucose-TGL & 263 & $0.23 \pm 0.26$ & 0.41 & $-0.02 \pm 0.16$ & 0.16 \\
\hline Fasting Insulin-BMI & 280 & $0.48 \pm 0.16$ & 0.01 & $0.33 \pm 0.14^{2}$ & 0.44 \\
\hline Fasting insulin-WC & 280 & $0.47 \pm 0.16$ & 0.02 & $0.30 \pm 0.16$ & 0.34 \\
\hline Fasting insulin-MUAC & 280 & $0.46 \pm 0.19$ & 0.05 & $0.33 \pm 0.12^{2}$ & 0.39 \\
\hline Fasting insulin-HDLc & 265 & $-0.47 \pm 0.18$ & 0.02 & $-0.04 \pm 0.19$ & -0.25 \\
\hline Fasting insulin-TGL & 265 & $0.03 \pm 0.25$ & 0.89 & $0.15 \pm 0.17$ & 0.07 \\
\hline HOMA-IR -BMI & 280 & $0.53 \pm 0.18$ & 0.02 & $0.29 \pm 0.13$ & 0.42 \\
\hline HOMA-IR -WC & 280 & $0.46 \pm 0.20$ & 0.05 & $0.28 \pm 0.14$ & 0.35 \\
\hline HOMA-IR -MUAC & 280 & $0.50 \pm 0.22$ & 0.07 & $0.29 \pm 0.11^{2}$ & 0.39 \\
\hline HOMA-IR -HDLc & 262 & $-0.58 \pm 0.21$ & 0.02 & $-0.05 \pm 0.19$ & -0.21 \\
\hline HOMA-IR-TGL & 261 & $-0.01 \pm 0.34$ & 0.96 & $0.20 \pm 0.14$ & 0.12 \\
\hline
\end{tabular}

All measures were $\log _{\mathrm{e}}$ transformed prior to analysis. $\rho e$ : environmental correlation; $\rho g$ : genetic correlation; $\rho p$ : phenotypic correlation calculated as $\rho p=\left[\sqrt{\mathrm{h} 1^{2}} \mathrm{x} \sqrt{\mathrm{h} 2^{2}} \mathrm{~g}\right]+\left[\sqrt{\left(1-\mathrm{h} 1^{2}+\mathrm{h} 2^{2}\right) \mathrm{e}}\right]$; SE: standard error; BMI: body mass index; MUAC: mid-upper arm circumference; HOMA-IR: homeostasis model assessment-insulin resistance; HDL: high-density lipoprotein; WC: waist circumference; TGL: triglycerides. $\mathrm{P}$ different from zero. All of the variables were significant for $\mathrm{P}$ different from one.

${ }^{1} \mathrm{p}$ value of genetic correlation, adjusted sex and age.

${ }^{2} \mathrm{p}<0.05$.

$3 \%$ of trait variation due to the pleiotropic effects of genes.

hypothesis and also provide the basis for future studies for the identification of genes that could provide insight into the nature of the insulin resistance syndrome, their components and other associated diseases.

In general, this study suggests the importance of environmental and additive genetic factors contributing to variations in glucose homeostasis and lipid levels that contribute to the high prevalence of obesity, hypertension and diabetes in this population.

\section{Financial Support}

This project was funded through grants from the National Institutes of Health (NIH-ICIDR Grant AI45451), USA, NCRI and Fundação de Amparo a Pesquisa do Estado de Minas Gerais-FAPEMIG. Gustavo Velásquez-Meléndez, Andrea Gazzinelli and Rodrigo Corrêa-Oliveira received grants from the Brazilian National Research Council (CNPq).

\section{Acknowledgements}

The authors would like to thank Dr. Jenefer Blackwell for providing the primer pairs used for genotyping and the confirmation of the pedigree data bank. We also thank to Pró-
Reitoria de Pesquisa of Universidade Federal de Minas Gerais for support in translation to the English version.

\section{References}

Aballay, L. R., Eynard, A. R., Díaz, M. D. P., Navarro, A. \& Muñoz, S. E. (2013) Overweight and obesity: a review of their relationship to metabolic syndrome, cardiovascular disease, and cancer in South America. Nutr Rev 71, 168-179.

Almasy, L. \& Blangero, J. (1998) Multipoint quantitative-trait linkage analysis in general pedigrees. Am J Hum Genet 62, 11981211.

Almasy, L., Dyer, T. D. \& Blangero, J. (1997) Bivariate quantitative trait linkage analysis: pleiotropy versus co-incident linkages. Genet Epidemiol 14, 953-958.

Arya, R., Duggirala, R., Comuzzie, A. G., Puppala, S., Modem, S., Busi, B. R. \& Crawford, M. H. (2002) Heritability of anthropometric phenotypes in caste populations of Visakhapatnam, India. Hum Biol 74, 325-344.

Austin, M. A., Newman, B., Selby, J. V., Edwards, K., Mayer, E. J. \& Krauss, R. M. (1993) Genetics of LDL subclass phenotypes in women twins. Concordance, heritability, and commingling analysis. Arterioscler Thromb 13, 687-695.

Bastard, J., Maachi, M., Lagathu, C., Kim, M., Caron, M., Vidal, H., Capeau, J. \& Feve, B. (2006) Recent advances in the relationship between obesity, inflammation, and insulin resistance. Eur Cytokine Netw 17, 4-12.

Bastarrachea, R. A., Kent, J. W., Jr., Rozada, G., Cole, S. A., Lopez-Alvarenga, J. C., Aradillas, C., Brito-Zurita, O., CerdaFlores, R. M., Ibarra-Costilla, E., Gallegos, E., Laviada-Molina, 
H., Hernandez-Escalante, V., Rosas, J., Machado, A., Vadillo, F., Ramos, M., Lazalde, B., Santa-Olalla, J., Maccluer, J. W. \& Comuzzie, A. G. (2007) Heritability and genetic correlations of metabolic disease-related phenotypes in Mexico: preliminary report from the GEMM Family Study. Hum Biol 79, 121129.

Bayoumi, R. A., Al-Yahyaee, S. A. S., Albarwani, S. A., Rizvi, S. G., Al-Hadabi, S., Al-Ubaidi, F. F., Al-Hinai, A. T., Al-Kindi, M. N., Adnan, H. T., Al-Barwany, H. S., Comuzzie, A. G., Cai, G., Lopez-Alvarenga, J. C. \& Hassan, M. O. (2007) Heritability of determinants of the metabolic syndrome among healthy Arabs of the Oman Family Study. Obesity 15, 551-556.

Bhopal, R. S. (2013) A four-stage model explaining the higher risk of type 2 diabetes mellitus in South Asians compared with European populations. Diabet Med 30, 35-42.

Bicalho, P. G., Hallal, P. C., Gazzinelli, A., Knuth, A. G. \& Velásquez-Meléndez, G. (2010) Atividade fisica e fatores associados em adultos de área rural em Minas Gerais, Brasil. Revista de Saúde Pública 44, 884-893.

Bo, S., Musso, G., Gambino, R., Villois, P., Gentile, L., Durazzo, M., Cavallo-Perin, P. \& Cassader, M. (2012) Prognostic implications for insulin-sensitive and insulin-resistant normal-weight and obese individuals from a population-based cohort. Am J Clin Nutr 96, 962-969.

Brown, W. M., Beck, S., Lange, E., Davis, C., Kay, C., Langefeld, C. \& Rich, S. (2003) Age-stratified heritability estimation in the Framingham Heart Study families. BMC Genet 4, S32. doi:10.1186/1471-2156-4-S1-S32.

Cameron, A. J., Magliano, D. J. \& Soderberg, S. (2013) A systematic review of the impact of including both waist and hip circumference in risk models for cardiovascular diseases, diabetes and mortality. Obes Rev 14, 86-94.

Dutra, M. S., Béla, S. R., Peixoto-Rangel, A. L., Fakiola, M., Cruz, A. G., Gazzinelli, A., Quites, H. F., Bahia-Oliveira, L. M. G., Peixe, R. G., Campos, W. R., Higino-Rocha, A. C., Miller, N. E., Blackwell, J. M., Antonelli, L. R. \& Gazzinelli, R. T. (2013) Association of a NOD2 Gene Polymorphism and T-Helper 17 cells with presumed ocular toxoplasmosis. J Infect Dis 207, 152-163.

Dyke, B. (1992) PEDSYS: A Pedigree Data Management System. Version: 2.0. Population Genetics Laboratory.

Freeman, M. S., Mansfield, M. W., Barrett, J. H. \& Grant, P. J. (2002) Heritability of features of the insulin resistance syndrome in a community-based study of healthy families. Diabet Med 19, 994-999.

Ghosh, A., Dutta, R. \& Sarkar, A. (2010) Heritability estimation of conventional cardiovascular disease risk factors in Asian Indian families: The Calcutta family study. Indian J Hum Genet 16, 28-32.

Godsland, I. F., Lecamwasam, K. \& Johnston, D. G. (2011) A systematic evaluation of the insulin resistance syndrome as an independent risk factor for cardiovascular disease mortality and derivation of a clinical index. Metabolism 60, 1442-1448.

Greenberg, A. S. \& Obin, M. S. (2006) Obesity and the role of adipose tissue in inflammation and metabolism. Am J Clin Nutr 83, 461S-465S.

Haffner, S. M., Stern, M. P., Hazuda, H. P., Mitchell, B. D. \& Patterson, J. K. (1988) Increased insulin concentrations in nondiabetic offspring of diabetic parents. N Engl J Med 319, 1297-1301.

He, Y. N., Feskens, E., Li, Y. P., Zhang, J., Fu, P., Ma, G. S. \& Yang, X. G. (2012) Association between high fat-low carbohydrate diet score and newly diagnosed type 2 diabetes in Chinese population. Biomed Environ Sci 25, 373-382.

Healy, G. N., Wijndaele, K., Dunstan, D. W., Shaw, J. E., Salmon, J., Zimmet, P. Z. \& Owen, N. (2008) Objectively measured sedentary time, physical activity, and metabolic risk: the Australian Diabetes, Obesity and Lifestyle Study (AusDiab). Diabetes Care 31, 369-371.

Henkin, L., Bergman, R. N., Bowden, D. W., Ellsworth, D. L., Haffner, S. M., Langefeld, C. D., Mitchell, B. D., Norris, J. M., Rewers, M., Saad, M. F., Stamm, E., Wagenknecht, L. E. \& Rich, S. S. (2003) Genetic epidemiology of insulin resistance and visceral adiposity: The IRAS Family Study Design and Methods. Ann Epidemiol 13, 211-217.

Heutink, P. \& Oostra, B. A. (2002) Gene finding in genetically isolated populations. Hum Mol Genet 11, 2507-2515.

Hopper, J. L. \& Mathews, J. D. (1983) Extensions to multivariate normal models for pedigree analysis. II. Modeling the effect of shared environment in the analysis of variation in blood lead levels. Am J Epidemiol 117, 344-355.

Lange, K. \& Boehnke, M. (1983) Extensions to pedigree analysis. IV. Covariance components models for multivariate traits. Am J Med Genet 14, 513-524.

Laws, A., Stefanick, M. L. \& Reaven, G. M. (1989) Insulin resistance and hypertriglyceridemia in nondiabetic relatives of patients with noninsulin-dependent diabetes mellitus. J Clin Endocrinol Metab 69, 343-347.

Lee, J., Chen, L., Snieder, H., Chen Da, F., Lee, L.M., Liu, G. F., Wu, T., Tang, X., Zhan, S. Y., Cao, W. H., Lv, J., Gao, W. J. \& Hu, Y. H. (2010) Heritability of obesity-related phenotypes and association with adiponectin gene polymorphisms in the Chinese national twin registry. Ann Hum Genet 74, 146-154.

Lin, H. F., Boden-Albala, B., Juo, S., Park, N., Rundek, T. \& Sacco, R. (2005) Heritabilities of the metabolic syndrome and its components in the Northern Manhattan Family Study. Diabetologia 48, 2006-2012.

Lohman, T. G., Roche, A. F. \& Martorell, R. (1988) Anthropometric Standardization Reference Manual. Champaign, IL: Human Kinetics Press.

Matos, A. C. \& Ladeia, A. M. (2003) Assessment of cardiovascular risk factors in a rural community in the Brazilian state of Bahia. Arq Bras Cardiol 81, 297-302.

Matthews, D., Hosker, J., Rudenski, A., Naylor, B., Treacher, D. \& Turner, R. (1985) Homeostasis model assessment: insulin resistance and $\beta$-cell function from fasting plasma glucose and insulin concentrations in man. Diabetologia 28, 412-419.

Mayer, E. J., Newman, B., Austin, M. A., Zhang, D., Quesenberry, C. P., Edwards, K. \& Selby, J. V. (1996) Genetic and environmental influences on insulin levels and the insulin resistance syndrome: an analysis of women twins. Am J Epidemiol 143, 323-332.

Mills, G., Avery, P., Mccarthy, M., Hattersley, A., Levy, J., Hitman, G., Sampson, M. \& Walker, M. (2004) Heritability estimates for beta cell function and features of the insulin resistance syndrome in UK families with an increased susceptibility to Type 2 diabetes. Diabetologia 47, 732-738.

Nagy, S., Poczai, P., Cernák, I., Gorji, A., Hegedűs, G. \& Taller, J. (2012) PICcalc: an online program to calculate polymorphic information content for molecular genetic studies. Biochem Genet 50, 670-672.

O'Connell, J. R. \& Weeks, D. E. (1998) PedCheck: a program for identification of genotype incompatibilities in linkage analysis. $\mathrm{Am}$ J Hum Genet 63, 259-266. 
Oliveira, C. D., Pereira, A., De Andrade, M., Soler, J. \& Krieger, J. (2008) Heritability of cardiovascular risk factors in a Brazilian population: Baependi Heart Study. BMC Med Genet 9, 32. doi: 10.1186/1471-2350-9-32.

Parra, F. C., Amado, R. C., Lambertucci, J. R., Rocha, J., Antunes, C. M. \& Pena, S. D. (2003) Color and genomic ancestry in Brazilians. Proc Natl Acad Sci USA 100, 177-182.

Pimenta, J. R., Zuccherato, L. W., Debes, A. A., Maselli, L., Soares, R. P., Moura-Neto, R. S., Rocha, J., Bydlowski, S. P. \& Pena, S. D. (2006) Color and genomic ancestry in Brazilians: a study with forensic microsatellites. Hum Hered 62, 190-195.

Rao, F., Chiron, S., Wei, Z., Fung, M. M., Chen, Y., Wen, G., Khandrika, S., Ziegler, M. G., Benyamin, B., Montgomery, G., Whitfield, J. B., Martin, N. G., Waalen, J., Hamilton, B. A., Mahata, S. K. \& O'Connor, D. T. (2012) Genetic variation within a metabolic motif in the chromogranin a promoter: pleiotropic influence on cardiometabolic risk traits in twins. Am J Hypertens 25, 29-40.

Reaven, G. M. (1997) Banting Lecture 1988. Role of insulin resistance in human disease. 1988. Nutrition 13, 65; discussion 64, 66.

Reilly, M. P. \& Rader, D. J. (2003) The metabolic syndrome. Circulation 108, 1546-1551.

Rice, T., Perusse, L., Bouchard, C. \& Rao, D. C. (1999) Familial aggregation of body mass index and subcutaneous fat measures in the longitudinal Quebec family study. Genet Epidemiol 16, 316334.

Schmidt, M. I., Watson, R. L., Duncan, B. B., Metcalf, P., Brancati, F. L., Richey Sharrett, A., Davis, C. E. \& Heiss, G. (1996) Clustering of dyslipidemia, hyperuricemia, diabetes, and hypertension and its association with fasting insulin and central and overall obesity in a general population. Metabolism 45, 699-706.

Shah, S. H., Hauser, E. R., Bain, J. R., Muehlbauer, M. J., Haynes, C., Stevens, R. D., Wenner, B. R., Dowdy, Z. E., Granger, C. B., Ginsburg, G. S., Newgard, C. B. \& Kraus, W. E. (2009) High heritability of metabolomic profiles in families burdened with premature cardiovascular disease. Mol Syst Biol 5, 258.

Shugart, Y. Y. \& Wang, Y. (2012) Identification of genotype errors. Methods Mol Biol 850, 11-24.

Souren, N., Paulussen, A., Loos, R., Gielen, M., Beunen, G., Fagard, R., Derom, C., Vlietinck, R. \& Zeegers, M. (2007) An- thropometry, carbohydrate and lipid metabolism in the East Flanders Prospective Twin Survey: heritabilities. Diabetologia 50, 21072116.

Sung, J., Lee, K. \& Song, Y. M. (2009) Heritabilities of the metabolic syndrome phenotypes and related factors in Korean Twins. J Clin Endocrinol Metab 94, 4946-4952.

Valle, A. M., Radić, Z., Rana, B. K., Mahboubi, V., Wessel, J., Shih, P. A. B., Rao, F., O'connor, D. T. \& Taylor, P. (2011) Naturally occurring variations in the human cholinesterase genes: heritability and association with cardiovascular and metabolic traits. J Pharmacol Exp Ther 338, 125-133.

Velasquez-Melendez, G., Parra, F. C., Gazzinelli, A., WilliamsBlangero, S. \& Correa-Oliveira, R. (2007) Genetic determinants of risk factors for cardiovascular disease in a population from rural Brazil. Hum Biol 79, 179-190.

Wagenknecht, L. E., Zaccaro, D., Espeland, M. A., Karter, A. J., O'leary, D. H. \& Haffner, S. M. (2003) Diabetes and progression of carotid atherosclerosis. Arterioscler Thromb Vasc Biol 23, 10351041.

Warren, D. M., Soria, J. M., Souto, J. C., Comuzzie, A., Fontcuberta, J., Blangero, J., Maccluer, J. W. \& Almasy, L. (2005) Heritability of hemostasis phenotypes and their correlation with type 2 diabetes status in Mexican Americans. Hum Biol 77, 1-15.

Williams-Blangero, S. \& Blangero, J. (2006) Collection of pedigree data for genetic analysis in isolate populations. Hum Biol 78, 89101.

Xiang, A. H., Azen, S. P., Buchanan, T. A., Raffel, L. J., Tan, S., Cheng, L. S. C., Diaz, J., Toscano, E., Quinonnes, M., Liu, C. R., Liu, C. H., Castellani, L. W., Hsueh, W. A., Rotter, J. I. \& Hodis, H. N. (2002) Heritability of subclinical atherosclerosis in latino families ascertained through a hypertensive parent. Arterioscler Thromb Vasc Biol 22, 843-848.

Zabaneh, D., Chambers, J., Elliott, P., Scott, J., Balding, D. \& Kooner, J. (2009) Heritability and genetic correlations of insulin resistance and component phenotypes in Asian Indian families using a multivariate analysis. Diabetologia 52, 25852589

Received: 5 March 2013

Accepted: 10 October 2013 